\title{
Evaluasi Ketepatan Pemberian Antibiotik Empirik Pada Pasien Demam Neutropenia Akibat Kemoterapi Di RSUP Dr Kariadi Semarang
}

\author{
Mida Pratiwi ${ }^{\text {a, }}{ }^{*}$, EM Sutrisna ${ }^{\text {b, } 1}$ \\ ${ }^{a}$ Universitas Aisyah Pringsewu, Lampung, Pringsewu, 35373 \\ ${ }^{\mathrm{b}}$ Universitas Muhammadiyah Surakarta, Sukoharjo, $575 \mathrm{II}$ \\ 1 midapratiwi28@gmai.com*; ${ }^{2}$ emsutrisna@ums.ac.id \\ *korespondensi penulis
}

\begin{tabular}{ll}
\hline INFO ARTIKEL & ABSTRAK \\
\hline Diterima : & Demam neutropenia merupakan keadaan yang ditandai dengan suhu dan angka \\
I4-06-202I & neutrofil meningkat. Neutropenia dapat terjadi akibat kemoterapi dan \\
Direvisi : & merupakan keadaan darurat yang dapat mengakibatkan infeksi serius dan harus \\
04-07-202I & mendapatkan terapi antibiotik empirik. Penelitian ini bertujuan untuk \\
Disetujui : & mengevaluasi ketepatan antibiotik empirik dengan metode gyssens pada pasien \\
O6-07-202I & kanker yang mengalami demam neutropenia. Penelitian ini menggunakan desain \\
& penelitian cross sectional dan diambil secara prospektif di RSUP Dr Kariadi \\
Kata kunci: & Semarang periode Juli-Oktober 20I9. Kriteria inklusi pada penelitian adalah \\
Kanker; & seluruh pasien kanker yang mengalami demam neutropenia dan mendapatkan \\
Kemoterapi; & antibiotik empirik. Data pasien yang diperoleh dari penelitian ini dianalisis dan \\
Demam; & akan dibandingkan dengan literatur. Hasil penelitian ini mendapatkan sebanyak \\
Neutropenia; & IOI pasien dengan $57,4 \%$ adalah perempuan dan $42,6 \%$ laki-laki. Sedangkan \\
Antibiotik. & untuk jenis kanker yang mengalami demam neutropenia dalam penelitian ini \\
& adalah $81,2 \%$ pasien kanker non solid dan I8,8\% kanker solid. Berdasarkan \\
diagram alir gyssens penggunaan antibiotik empirik pada pasien demam \\
neutropenia yang tepat pada penelitian ini adalah sebesar $74,3 \%$ dan tidak tepat \\
sebesar $25,7 \%$.
\end{tabular}

Key word:
Cancer;
Chemotheraphy;
Febrile;
Neutropenia;
Antibiotic.

\section{ABSTRACT}

Febrile neutropenia is a state of apprehension with increased temperature and neutrophil count. Neutropenia can occur due to chemotherapy and emergencies that can lead to serious infections and should receive antibiotic therapy. Yhis study aims to achieve antibiotic accuracy with the gyssens method in cancer patients with febrile neutropenia. The study used a cross-sectional study design and was taken prospectively at the Hospital RSUP Dr Kariadi period JulyOctober 2019. The inclusion criteria in the study were all patients who had febrile neutropenia and received empirical antibiotics. Patient data obtained from this study were analyzed and compared with the literature and then performed statistical analysis. The result of the study were IOI patient with $57,4 \%$ being female and $42,6 \%$ male. Meanwhile, the types of cancer that had febrile neutropenia in this study were $81,2 \%$ of non solid cancer patients and I8,8\% of solid cancers. Based on the gyssens flow chart the use of empiric antibiotic in patient febrile neutropenia was $74,3 \%$ and $25,8 \%$ incorrect.

This is an open access article under the CC-BY-SA license.

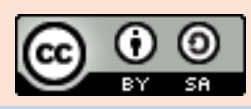

\section{Pendahuluan \\ Demam neutropenia merupakan efek samping yang serius akibat pemberian kemoterapi dan berhubungan signifikan terhadap angka kematian pasien kanker bahkan dapat menyebabkan penundaan pada pemberian kemoterapi selanjutnya (Cameron,}

2009). Demam neutropenia adalah kondisi suhu tubuh $\geq 38^{\circ} \mathrm{C}$ yang bersamaan dengan neutropenia atau nilai Absolute Nuetrophil Count (ANC) yang terus menurun sampai $\leq 500 \mathrm{sel} / \mathrm{mm}^{3}$.

Pada kondisi dengan sistem kekebalam tubuh yang lemah demam merupakan salah satu tanda infeksi 
yang mendasar dan pengobatan harus segera diberikan (Lucas et al., 2018). Penilaian terhadap tanda dan gejala yang dialami oleh pasien demam neutropenia dapat mengidentifikasi pasien tersebut termasuk dalam resiko rendah maupun resiko tinggi terjadinya infeksi (Fontanella et al., 20I4). Penggunaan Granulocyte-Colony stimulating factors (GCSF) atau antibiotik pada pasien kanker dengan demam neutropenia dapat mengurangi angka kejadian infeksi (Fernandes et al., 2017).

Kondisi demam neutropenia dengan resiko infeksi membutuhkan pencegahan menggunakan antibiotik empirik (Sosa et al., 2017). Pemberian antibiotik yang tepat akan menghasilkan efek yang baik pada pasien kanker dengan demam neutropenia. Pada tahun 1992 Gyssens et al mengembangkan suatu diagram alur untuk mengevaluasi peresepan antimikroba seperti dasar kebenaran resep antibiotik yang akan diberikan, alternatif lebih efektif, dosis dan cara pemberian antibiotik yang tepat. Evaluasi penggunaan antibiotik selain bertujuan untuk mengetahui jumlah penggunaan antibiotik juga dapat dijadikan sebagai dasar dalam menetapkan penggunaan antibiotik yang terstandar dalam pelayanan di rumah sakit (Kemenkes RI, 20II).

\section{Metode}

Penelitian ini menggunakan jenis penelitian observasional dengan rancangan cross sectional dilakukan melalui penelusuran rekam medik pasien kanker dengan demam neutropenia pada saat menggunakan antibiotik empirik. Penilaian ketepatan dalam pemilihan antibiotik empirik dengan metode gyssens pada pasien demam neutropenia dilakukan selama 4 bulan mulai dari Juli-Oktober 2019 di RSUP Dr Kariadi Semarang.

Analisis data yang dilakukan pada penelitian ini adalah dengan membandingkan data yang diperoleh dengan pedoman penggunaan antibiotik empirik untuk pasien demam neutropenia dari ESMO (European Society for Medical Oncology) dan NCCN (National Comprehensive Cancer Network) serta berdasar pada diagram alir yang ada pada metode gyssens.

\section{Hasil dan Pembahasan}

\section{Karakteristik pasien}

Karakteristik subjek penelitian menggunakan analisis data deskriptif yang merupakan gambaran dari suatu variabel. Karakteristik pasien kanker dengan demam neutropenia yang dibahas dikelompokkan berdasarkan jenis kelamin, usia, jenis kanker dan durasi neutropenia dari pasien yang dapat dilihat pada Tabel I.
Karakteristik dari pasien dapat dilihat pada tabel I bahwa jumlah pasien kanker dengan demam neutropenia yang diterapi dengan menggunakan antibiotik empirik di RSUP Dr Kariadi Semarang adalah sebanyak 58 pasien $(57,4 \%)$ dengan jenis kelamin perempuan dan sebanyak 43 pasien $(42,6 \%)$ dengan jenis kelamin laki-laki. Pada penelitian yang dilakukan oleh (Sosa et al., 2017) yang melaporkan bahwa pasien kanker yang memiliki resiko tinggi terjadinya demam neutropenia dengan jenis kelamin perempuan lebih banyak daripada pasien demam neutropenia dengan jenis kelamin laki-laki.

Tabel I. Karakteristik Pasien dengan Demam Neutropenia di RSUP Dr Kariadi

\begin{tabular}{lcc}
\multicolumn{3}{c}{ Semarang } \\
\hline Karakteristik & Jumlah (n) & Persentase (\%) \\
\hline Jenis kelamin & & \\
Perempuan & 58 & 57,4 \\
Laki-laki & 43 & 42,6 \\
Kelompok usia & & \\
0-I7 tahun & 35 & 34,7 \\
I8-60 tahun & 59 & 58,4 \\
$>60$ tahun & 7 & 6,9 \\
Jenis kanker & & \\
Non solid & 82 & 81,2 \\
Solid & 19 & 18,8 \\
Durasi & & \\
neutropenia & & \\
$\leq 7$ hari & 45 & 44,6 \\
$>7$ hari & 56 & 55,4 \\
\hline
\end{tabular}

Pasien kanker yang mengalami demam neutropenia memiliki resiko kematian yang lebih besar jika tidak ditangani dengan baik lebih banyak terjadi pada perempuan sebesar $(83,39 \%)$ daripada pasien kanker dengan jenis kelamin laki-laki (I6,6I\%) (Lyman et al., 20I0). Beberapa penelitian menjelaskan bahwa jenis kelamin perempuan sebagai faktor resiko yang signifikan untuk terjadinya demam neutropenia dibandingkan pasien kanker dengan jenis kelamin lakilaki. Resiko kejadian demam neutropenia dengan jenis kelamin perempuan kemungkinan karena efek hormon gender atau peningkatan insiden penyakit autoimun pada wanita yang tidak diketahui penyebabnya (Badr et al., 2016).

Pengambilan sampel untuk penelitian ini adalah semua pasien kanker yang mengalami demam neutropenia akibat kemoterapi di RSUP Dr Kariadi Semarang. Pengelompokkan berdasarkan usia pasien dalam penelitian ini dibagi dalam tiga kelompok berdasarkan World Health Organization (WHO) yaitu usia anak adalah kisaran $<$ I8 tahun sebanyak 35 pasien $(34,7 \%)$, usia dewasa I8-60 tahun sebanyak 59 pasien $(58,4 \%)$ dan lanjut usia adalah usia $>60$ tahun sebanyak 7 pasien (6,9\%). Pasien dengan usia dewasa dengan rentang $\leq 60$ tahun merupakan faktor 
resiko terjadinya demam neutropenia (Zhai et al., 20I5). Penelitian yang dilakukan oleh (Castela et al., 2016) menemukan bahwa populasi pasien kanker yang banyak ditemukan untuk kejadian demam neutropenia adalah pasien dewasa.

Jenis kanker yang mengalami demam neutropenia akibat penggunaan obat kemoterapi sangat beragam. Namun, penelitian ini mengelompokkan berdasarkan kanker solid dan non solid. Kanker solid merupakan kanker padat yang terjadi akibat benjolan yang padat dan terjadi di bagian atau dalam tubuh pasien. Sedangkan untuk kanker non solid adalah kanker darah yang diderita oleh pasien. Pada penelitian ini, didapatkan kanker non solid adalah sebanyak 82 pasien (8I,2\%) dan kanker solid sebanyak I9 pasien (18,8\%). Penelitian yang juga dilakukan oleh (Jacob et al., 20I4) terkait insidensi terjadinya demam neutropenia pada individu yang menderita tumor padat dan keganasan hematologi yang sedang menjalani kemoterapi didapatkan kejadian demam neutropenia pada tumor padat adalah sebanyak 32 pasien (42,7\%) dan keganasan hematologi sebanyak 43 pasien (57,3\%).

Faktor resiko tinggi terjadinya demam neutropenia dan infeksi adalah karena durasi neutropeni yang berkeperpanjangan dari pasien atau sekitar $>7$ hari semenjak terjadinya penurunan Absolute Neutrofil Count (ANC) kurang dari 500 $\mathrm{sel} / \mathrm{mm}^{3}$ (Freifeld et al., 20II). Pada penelitian ini durasi neutropenia dibedakan menjadi 2 kelompok berdasarkan resiko infeksi pada pasien, yaitu kelompok pasien dengan durasi neutropenia $\leq 7$ hari dan $>7$ hari terhitung saat pasien di rumah sakit mengalami penurunan nilai ANC setelah mendapatkan kemoterapi. Hasil yang diperoleh dalam penelitian ini adalah sebanyak 45 pasien $(44,6 \%)$ dengan durasi neutropenia $\leq 7$ hari dan pasien dengan durasi neutropenia $>7$ hari adalah sebanyak 56 pasien $(55,4 \%)$. Pada penelitian yang dilakukan oleh (Zhai et al., 2015) pasien kanker yang mengalami neutropenia lebih panjang ( $>$ 2hari) akan meningkatkan resiko untuk terjadinya demam neutropenia sebesar $53,7 \%$ dibandingkan pasien dengan durasi neutropenia $\leq 2$ hari sebesar $45,3 \%$. Ketika neutropenia berat yang berkelanjutan menjadi demam neutropenia diyakini terkait dengan produksi sitokin yang bertanggung jawab untuk mengaktifkan respon imun untuk terjadinya demam. Produksi sitokin biasanya dimediasi oleh pirogen eksogen (Rasmy et al., 2016).

\section{Penggunaan antibiotik pada penelitian}

Antibiotik empirik yang disarankan adalah antibiotik dengan spektrum luas. Pasien demam neutropenia harus dirawat dengan pengamatan ketat sampai nilai ANC minimal $>500 \mathrm{sel} / \mathrm{mm}^{3}$ (Rasmy et al., 2016). Pencegahan infeksi pada pasien demam neutropenia dimaksudkan untuk mengurangi angka kesakitan dan kematian pada pasien kanker. Pasien kanker yang mengalami demam neutropenia akibat kemoterapi dalam penelitian ini sebanyak IOI pasien. Gambaran penggunaan antibiotik empirik dapat dilihat pada Tabel 2 sebagai berikut :

Tabel 2. Gambaran Penggunaan Antibiotik Empirik pada Pasien Demam Neutropenia

\begin{tabular}{lccc}
\hline Karakteristik & Rute & $\begin{array}{c}\text { Jumlah } \\
\text { (n) }\end{array}$ & $\begin{array}{c}\text { Persentase } \\
(\%)\end{array}$ \\
\hline Cefepime & Intravena & 78 & 77,2 \\
Meropenem & Intravena & 8 & 7,92 \\
Ampisilin- & Intravena & I0 & 9,90 \\
sulbaktam & & & \\
Seftriakson & Intravena & I & 0,99 \\
Ciprofloksasin & Per-oral & 4 & 3,96 \\
\hline \multicolumn{1}{c}{ Jumlah } & & IOI & I00 \\
\hline
\end{tabular}

Menurut guideline terapi penggunaan antibiotik empirik pada pasien kanker dengan demam neutropenia seperti ESMO (European Society for Medical Oncology) dan NCCN (National Comprehensive Cancer Network adalah monoterapi dengan antipseudomonal beta laktam seperti cefepime, carbapenem (meropenem atau imipenem) dan piperacilin-tazobaktam (Freifeld et al., 20II). Pada tabel 2 menunjukan bahwa penggunaan antibiotik empirik pada pasien kanker dengan demam neutropenia di ruang isolasi RSUP Dr Kariadi Semarang adalah cefepime injeksi diberikan kepada 78 pasien $(77,2 \%)$, meropenem injeksi sebanyak 8 pasien (7,92\%), ampisilin-sulbaktam injeksi sebanyak I0 pasien $(9,90 \%)$, seftriakson injeksi sebanyak I pasien $(0,99 \%)$ dan ciprofloxacin secara peroral diberikan kepada 4 pasien (3,96\%).

Cefepime telah disetujui untuk digunakan secara klinis sejak 1996 dan tidak lama setelah itu, Food and Drug Administration (FDA) menyetujui cefepime untuk terapi empirik pada pasien demam neutropenia (Andreatos et al., 2017). Antibiotik lini pertama untuk pasien kanker dengan demam neutropenia untuk pasien anak dan dewasa adalah cefepime, ceftazidime, meropenem atau piperacilintazobaktam (Han et al., 2013). Selain cefepime, penggunaan antibiotik lain yang dapat direkomendasikan untuk pasien demam neutropenia adalah meropenem dan ceftazidime. Demam neutropenia yang terjadi pada pasien kanker berhasil diobati dengan antipseudomonal spektrum luas sefalosporin atau karbapenem (Erbey et al., 2010). 


\section{Evaluasi ketepatan antibiotik empirik}

Pada penelitian ini, data penelitian yang diambil pada periode Juli-Oktober 2019 dan memenuhi kriteria inklusi adalah IOI pasien yang kemudian dilakukan evaluasi terhadap antibiotik empirik yang diberikan pada pasien kanker dengan demam neutropenia menggunakan alur gyssens. Alur gyssens merupakan alur untuk mengetahui ketepatan atau rasionalitas penggunaan antibiotik pada pasien (Kemenkes RI, 20II). Evaluasi antibiotik menggunakan gyssens akan menentukan antibiotik yang digunakan termasuk dalam antibiotik rasional atau tidak berdasarkan kategori yang telah ditentukan dalam alur tersebut. Penggunaan antibiotik yang rasional dan tidak rasional pada pasien kanker dengan demam neutropenia dapat dilihat pada tabel 3 sebagai berikut:

Tabel 3. Rasionalitas Penggunaan Antibiotik Empirik Berdasarkan Alur Gyssens

\begin{tabular}{lcc}
\hline $\begin{array}{c}\text { Rasionalitas } \\
\text { antibiotik }\end{array}$ & $\begin{array}{c}\text { Jumlah } \\
\text { (n) }\end{array}$ & $\begin{array}{c}\text { Persentase } \\
(\%)\end{array}$ \\
\hline Tepat & 75 & 74,3 \\
Tidak tepat & 26 & 25,7 \\
\hline Jumlah & IOI & I00 \\
\hline
\end{tabular}

Evaluasi yang dilakukan pada pasien kanker dengan demam neutropenia di RSUP Dr Kariadi Semarang periode Juli-Oktober 2019. Data yang telah dievaluasi dengan menggunakan alur gyssens kemudian dikelompokkan menjadi dua kelompok besar yaitu kelompok yang dinilai mendapatkan antibiotik rasional dan kelompok antibiotik tidak rasional. Hasil penelitian menunjukkan bahwa pasien yang menerima antibiotik rasional berdasarkan metode gyssens adalah sebanyak 75 pasien $(74,3 \%)$ dan antibiotik yang tidak rasional adalah sebanyak 26 pasien $(25,7 \%)$.

Selanjutnya dari evaluasi ketepatan antibiotik empirik pada pasien demam neutropenia yang telah dilakukan dengan diagram alir gyssens, dilakukan analisis sebaran penggunaan antibiotik yang tidak rasional dan didapatkan hasil terbanyak terjadi adalah kategori IVa sebanyak II pasien (I0,8\%), kategori IVc 8 pasien (7,92\%), kategori IIIb I pasien (0,99\%), kategori IIa 2 pasien (I,98\%) dan kategori IIC sebanyak 4 pasien $(3,96 \%)$. Berdasarkan evaluasi penggunaan antibiotik dengan menggunakan alur gyssens permasalahan penggunaan antibiotik yang tidak tepat paling banyak berkaitan dengan terdapat alternatif yang lebih efektif (kategori IVa).

Sebaran penggunaan antibiotik yang dinilai tidak rasional pada pasien kanker dengan demam neutropenia di RSUP Dr Kariadi Semarang periode Juli-Oktober 2019 dalam penelitian berdasarkan metode dan alur gyssens dapat dilihat pada tabel 4 sebagai berikut:

Tabel 4. Sebaran Penggunaan Antibiotik Empirik Tidak Rasional Berdasarkan Alur Gyssens

\begin{tabular}{|c|c|c|c|}
\hline & Kategori & $\begin{array}{c}\text { Jumlah } \\
\text { (n) }\end{array}$ & $\begin{array}{c}\text { Persentase } \\
(\%)\end{array}$ \\
\hline $\mathrm{IVa}$ & $\begin{array}{l}\text { Ada antibiotik lain } \\
\text { yang lebih efektif }\end{array}$ & II & 10,8 \\
\hline IVc & $\begin{array}{l}\text { Ada antibiotik lain } \\
\text { yang lebih murah }\end{array}$ & 8 & 7,92 \\
\hline IIIa & Durasi terlalu lama & I & 0,99 \\
\hline IIa & $\begin{array}{l}\text { Dosis pemberian } \\
\text { antibiotik tidak } \\
\text { tepat }\end{array}$ & 2 & $\mathrm{I}, 98$ \\
\hline IIc & $\begin{array}{l}\text { Rute pemberian } \\
\text { tidak tepat }\end{array}$ & 4 & 3,96 \\
\hline & Jumlah & 26 & 25,7 \\
\hline
\end{tabular}

Pada penelitian ini, umumnya pemberian terapi empirik pada pasien kanker yang mengalami demam neutropenia akibat kemoterapi sudah sesuai berdasarkan guideline terapi yaitu lini pertama adalah cefepime dan alternatif lain adalah meropenem. Namun, pemberian antibiotik ampisilin-sulbaktam pada pasien demam neutropenia ditemukan pada beberapa penelitian telah banyak terjadi resistensi. Sedangkan pemberian seftriakson mengakibatkan efek samping penurunan angka neutrofil sehingga dapat menyebabkan neutropenia dan penggunaan ciprofloksasin monoterapi secara peroral tidak direkomendasikan untuk pasien kanker yang mengalami demam neutropenia akibat kemoterapi (Freifeld et al., 2011).

\section{Simpulan dan Saran}

Penggunaan antibiotik empirik yang tepat pada pasien kanker dengan demam neutropenia menurut metode gyssens dalam penelitian ini sebesar $74,3 \%$ dan $25,7 \%$ tidak tepat.

Saran untuk penelitian selanjutnya adalah perlu dilakukan penelitian lebih lanjut terhadap pengaruh ketepatan dan faktor resiko infeksi terhadap efektivitas terapi antibiotik empirik pada pasien kenker dengan demam neutropenia.

\section{Ucapan Terima Kasih}

Penulis mengucapkan terimakasih kepada pembimbing dan pihak Rumah Sakit Umum Pusat Dr Kariadi Semarang yang telah membantu dalam pelaksanaan dan kelancaran penelitian ini. 


\section{Daftar Pustaka}

Andreatos, N. et al. (2017) 'The Dose-Dependent Efficacy of Cefepime in the Empiric Management of Febrile Neutropenia: A Systematic Review and Meta-Analysis', Open Forum Infectious Disease, pp. I-IO. doi: I0.I093/ofid/ofxII3.

Badr, M. et al. (2016) 'Chemotherapy - induced neutropenia among pediatric cancer patients in Egypt: Risks and consequences', Molecular and Clinical Oncology, pp. 300-306. doi: I0.3892/mco.2016.957.

Castela, O. D. et al. (2016) 'Risk Factors for Febrile Neutropenia in Children With Solid Tumors Treated With Cisplatin-based Chemotherapy', Journal Pediatric Hematology Oncology, 38(3), pp. I9I-I96.

Erbey, F. et al. (2010) 'Meropenem Monotherapy as an Empirical Treatment of Febrile Neutropenia in Childhood Cancer Patients', Asian Pasific Journal of Cancer Prevention, I I, pp. I23-I26.

Fernandes, R. et al. (2017) 'Optimal primary febrile neutropenia prophylaxis for patients receiving docetaxel-cyclophosphamide chemotherapy for breast cancer: a systematic review', Breast Cancer Research and Treatment. Springer US, I6I(I).

Freifeld, A. G. et al. (20I I) 'Clinical practice guideline for the use of antimicrobial agents in neutropenic patients with cancer: 2010 Update by the Infectious Diseases Society of America', Clinical Infectious Diseases, 52(4).

Han, S. B. et al. (2013) 'Clinical characteristics and antimicrobial susceptibilities of viridans streptococcal bacteremia during febrile neutropenia in patients with hematologic malignancies : a comparison between adults and children', BMC Infectious Disease, I3(273), p. I 472334

Jacob, L. et al. (2014) 'Clinical and Microbiological profile of Febrile Neutropenia in Solid Tumor and Hematological Malignancies at a Tertiary Cancer care center in South India', Indian Journal of Cancer, 5I(4), pp. 464-468.

Kemenkes RI (20II) 'Pedoman pelayanan kefarmasian untuk terapi antibiotik', Kementrian Kesehatan RI., Direktorat Jenderal Bina Kefarmasian dan Alat Kesehatan.

Lyman, G. H. et al. (2010) 'Risk of Mortality in Patients With Cancer Who Experience Febrile Neutropenia', American Cancer Society, pp. 5555-5563.

Rasmy, A. et al. (2016) 'Febrile Neutropenia in Cancer Patient: Epidemiology, Microbiology , Pathophysiology and Management', Journal of Cancer Prevention and Current Research, $5(3)$.

Sosa, R. et al. (2017) 'Use of prophylactic growth factors and antimicrobials in elderly patients with cancer: a review of the Medicare database', Supportive Care in Cancer. Supportive Care in Cancer, 25(I0), pp. 3123-3132.

Zhai, W. et al. (2015) 'A Prospective Observational Study of Antibiotic Therapy in Febrile Neutropenia Patients with Hematological Malignances from Multiple centers in Northeast China', International Journal of Infectious Diseases. International Society for Infectious Diseases, 37, pp. 97-I03. 